\title{
SfM-Based Method to Assess Gorgonian Forests (Paramuricea clavata (Cnidaria, Octocorallia))
}

\author{
Marco Palma ${ }^{1}$ (D), Monica Rivas Casado 2,* (D), Ubaldo Pantaleo ${ }^{3}$, Gaia Pavoni ${ }^{4}$, \\ Daniela Pica ${ }^{1}$ and Carlo Cerrano ${ }^{1}$ id \\ 1 Dipartimento di Scienze della Vita e dell'Ambiente (DISVA), Via Brecce Bianche, Monte Dago, \\ 60130 Ancona, Italy; m.palma@pm.univpm.it (M.P.); d.pica@univpm.it (D.P.); c.cerrano@univpm.it (C.C.) \\ 2 School of Water, Energy and Environment, Cranfield University, Cranfield MK430AL, UK \\ 3 UBICA srl (Underwater BIo-CArtography), Via San Siro 6 int.1, 16124 Genova, Italy; info@ubicasrl.com \\ 4 Istituto Superiore Tecnologia Italiana (ISTI), Consiglio Nazionale delle Ricerche (CNR), \\ Via Giuseppe Moruzzi 1, 56124 Pisa, Italy; gaia.pavoni@isti.cnr.it \\ * Correspondence: m.rivas-casado@cranfield.ac.uk
}

Received: 21 June 2018; Accepted: 17 July 2018; Published: 21 July 2018

\begin{abstract}
Animal forests promote marine habitats morphological complexity and functioning. The red gorgonian, Paramuricea clavata, is a key structuring species of the Mediterranean coralligenous habitat and an indicator species of climate effects on habitat functioning. P. clavata metrics such as population structure, morphology and biomass inform on the overall health of coralligenous habitats, but the estimation of these metrics is time and cost consuming, and often requires destructive sampling. As a consequence, the implementation of long-term and wide-area monitoring programmes is limited. This study proposes a novel and transferable Structure from Motion (SfM) based method for the estimation of gorgonian population structure (i.e., maximal height, density, abundance), morphometries (i.e., maximal width, fan surface) and biomass (i.e., coenenchymal Dry Weight, Ash Free Dried Weight). The method includes the estimation of a novel metric (3D canopy surface) describing the gorgonian forest as a mosaic of planes generated by fitting multiple $5 \mathrm{~cm} \times 5 \mathrm{~cm}$ facets to a SfM generated point cloud. The performance of the method is assessed for two different cameras (GoPro Hero4 and Sony NEX7). Results showed that for highly dense populations (17 colonies $/ \mathrm{m}^{2}$ ), the SfM-method had lower accuracies in estimating the gorgonians density for both cameras $(60 \%$ to $89 \%$ ) than for medium to low density populations (14 and 7 colonies $\left./ \mathrm{m}^{2}\right)(71 \%$ to $100 \%)$. Results for the validation of the method showed that the correlation between ground truth and SfM estimates for maximal height, maximal width and fan surface were between $R^{2}=0.63$ and $R^{2}=0.9$, and $R^{2}=0.99$ for coenenchymal surface estimation. The methodological approach was used to estimate the biomass of the gorgonian population within the study area and across the coralligenous habitat between -25 to $-40 \mathrm{~m}$ depth in the Portofino Marine Protected Area. For that purpose, the coenenchymal surface of sampled colonies was obtained and used for the calculations. Results showed biomass values of dry weight and ash free dry weight of $220 \mathrm{~g}$ and $32 \mathrm{~g}$ for the studied area and to $365 \mathrm{~kg}$ and $55 \mathrm{Kg}$ for the coralligenous habitat in the Marine Protected Area. This study highlighted the feasibility of the methodology for the quantification of $P$. clavata metrics as well as the potential of the SfM-method to improve current predictions of the status of the coralligenous habitat in the Mediterranean sea and overall management of threatened ecosystems.
\end{abstract}

Keywords: animal forest; point cloud classification; Good Environmental Status; environmental accounting; conservation 


\section{Introduction}

The term animal forest refers to the underwater population of suspension feeders mainly represented by sponges, cnidarians and bivalves which are well known for enhancing the morphological complexity of the seascape and structuring the habitat of the communities, thus promoting their functionalities [1]. In the Mediterranean Sea, animal forests are well represented by several octocoral species such as the gorgonian Paramuricea clavata (Risso, 1826). This is a slow-growing, long-lived and low fecundity species which forms dense forests along outcrops, cliffs and biogenic substrates [2] from $-15 \mathrm{~m}$ to $-200 \mathrm{~m}$ depth $[3,4]$. P. clavata is of special interest in coralligenous habitats because its canopy reduces the range of environmental variability and supports key associated biota [3,5,6]. The annual linear growth rate for the species ranges between $2.7 \mathrm{~cm}$ and $3.0 \mathrm{~cm}$, with larger rates observed for smaller colonies [7]. The shape of the fan, its growth and orientation adapt to local water current regimes, with the maximal filtration surface always opposing the water flow to maximize feeding efficiency [8]. In return, the drag effect of the fans promotes particle retention, this supporting both invertebrate and vertebrate and favoring the trophic energy transfer between benthos and plankton [9].

As cold-affinity species, $P$. clavata has a high sensitivity to thermal stress $[10,11]$ and is therefore considered an indicator species of climate effects on benthic assemblages [12]. In the last decades, the gorgonian forests in the Mediterranean Sea have been affected by mass mortality events triggered by water temperature anomalies that have led to functional changes in the coralligenous habitat, and to local extinctions of the species in shallow waters [6,13-20]. Moreover, the short larval dispersion of P. clavata could inhibit genetic exchanges between populations increasing their genetic isolation and limit the species recovery to mass mortality events [21].

Multiple structural, morphological and biomass metrics have been used to describe the status (or quality) of gorgonian forests [7,22-24]. For example, the linear growth and density of colonies, the basal diameter, and the coenenchymal ash free dry weight inform about the population's structure, the secondary production and the growth, which in combination with the sex ratio and the characteristics of the gonads (number, dimension and dry weight) provides insight into the population's conservation status and the state of evolution $[7,22,24,25]$. The rectangular fan surface, calculated as the product of the maximal height and the maximal width of the fan, informs about the age of the colony [26], whereas the epibiosis typology and coverage of the colonies highlight the intensity of the mechanical impacts that the colonies have been exposed to [24]. These metrics are therefore critical to (i) monitor changes in the population structure over time [3,12], (ii) quantify the magnitude of environmental disturbances [27] and (iii) assess the recovery capacity of the populations [20].

In recent years, the up-take of new technologies has supported researchers and surveyors with the collection of in-situ data. Structure from Motion (SfM) photogrammetry based methods are perhaps the most successful example within the context of benthic community mapping [28-30]. SfM is a topographic survey technique for the reconstruction of real scale three dimensional models of subjects or scenarios, using imagery collected at unknown camera positions [31]. It enables non-destructive, repeatable measurements and facilitates rapid sampling [28]. Applications of SfM surveying methods in terrestrial and seascape environments have provided accuracies and resolutions comparable to more sophisticated technologies (e.g., laser scanning) [30,32] and therefore, show great potential for the estimation of gorgonian structural and morphological metrics. The accuracy of SfM in estimating habitat complexity and morphometries of massive organisms and branched hard corals has been recently assessed by other authors [29,33-35] but none previously characterized erected and branched soft corals such as gorgonian species, even though SfM could provide an effective way forward towards assessing colonies' sizes and density, as well as biomass across habitats. With an increasing need to rapidly characterize gorgonian size, density and biomass being more prominent than ever under an economically constrained scenario and increased antrophogenic and climate pressures, the potential of SfM methods to fill this gap in knowledge cannot be left unexplored.

In Palma et al. [30], we developed an SfM based framework for the design of robust monitoring programmes of African coral reefs. Here, we propose a method for the estimation of density, 
abundance and key P. clavata morphometrics in gorgonian forests through segmentation and analysis of scaled point clouds generated by SfM photogrammetry. This is achieved through the following objectives: 1-To develop a SfM based framework for the automated and accurate estimation of P. clavata density, abundance, maximal height, maximal width, fan surface and biomass; 2-To assess the performance of the SfM method using two cameras representative of different market segments. 3-To demonstrate the usefulness of the method for the estimation of the gorgonian forests biomass within the Marine Protected Area of Portofino (Punta del Faro, Italy); 4-To discuss the relevance of the proposed method in line with current practice in gorgonian forest monitoring and its implications for future $P$. clavata research and management.

\section{Materials and Methods}

\subsection{Study Site}

The study site is located in the Marine Protected Area of Portofino (Punta del Faro, Italy) (44.298414N, 9.218549E, WGS84) and extends along $52 \mathrm{~m}^{2}$. The sampling was carried out between $-32 \mathrm{~m}$ to $-36 \mathrm{~m}$ along the West-East oriented cliff of Punta del Faro (Figure 1). In the area, the gorgonian forest underwent four consecutive mass mortality episodes in 1999, 2003, 2008 and 2013 that led to a progressively fragmented distribution of the colonies with increasing depth and the species extinction above $-20 \mathrm{~m}[15,17,36]$.

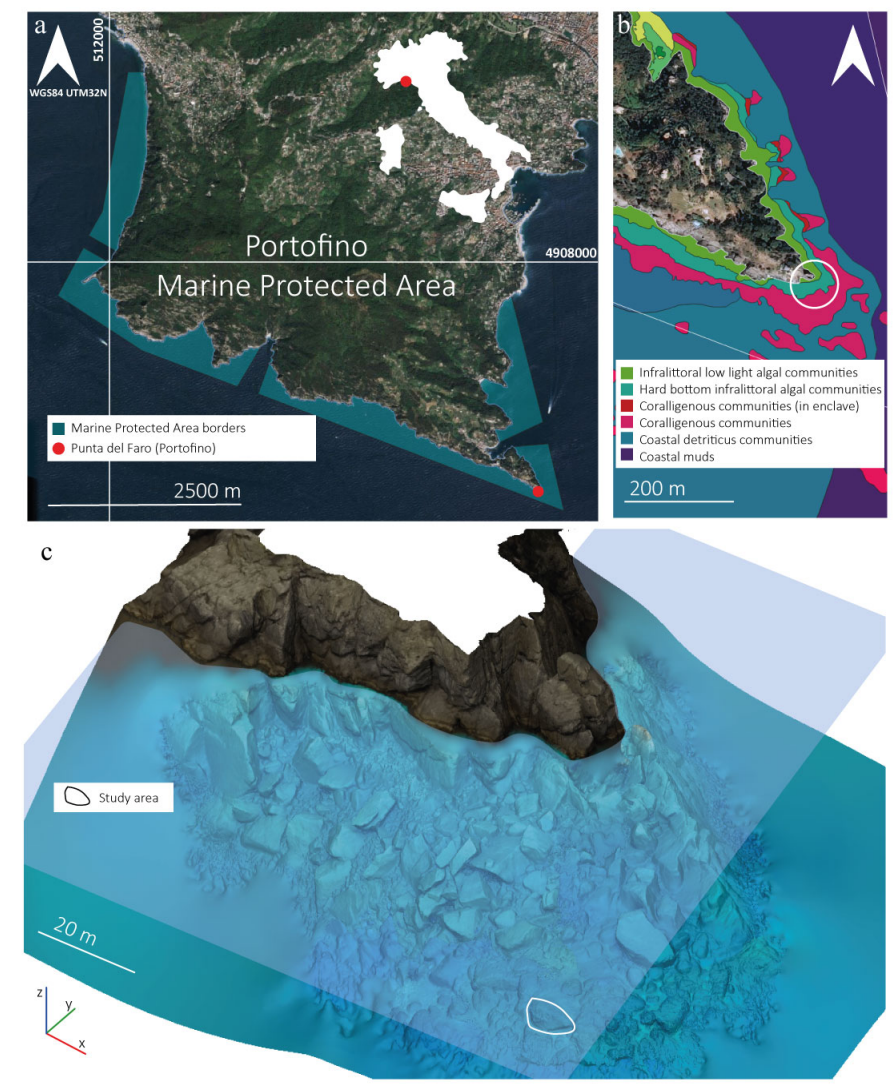

Figure 1. The study site in the Marine Protected Area of Portofino (Punta del Faro, Italy). (a) The border of the Marine Protected Area; (b) a detailed view of the benthic biocenosis mapped in the location of the study site using shapefiles available from [37]; (c) 3D view of the seabed around the study site at Punta del Faro (white polyline) generated via SfM using imagery collected on site. 


\subsection{Data Collection}

\subsubsection{Pilot Study on Gorgonian Population Structure}

A pilot study was carried out to characterize the gorgonian population structure within the case study area and inform on whether further survey campaigns should consider stratification of the sampling within the study site. Standard sampling quadrats $(n=14,0.5 \mathrm{~m} \times 0.5 \mathrm{~m})$ were used to record (i) the density of the colonies per quadrat, (ii) the maximal colony height, and (iii) the maximal colony width $[38,39]$. The survey showed that $P$. clavata had an heterogeneous spatial distribution in the study site and that three different density areas could be identified for the species: high, medium, low. Each density area will be referred to as stratum and the analysis will be performed for all strata.

\subsubsection{Underwater Imagery Collection}

Photogrammetric surveys were performed using two different cameras: (i) a Gopro Hero4 Black Edition (Woodman Labs, Inc., San Mateo, CA, US) and (ii) a Sony NEX7 alpha digital camera (Sony Corporation, Minato, Tokyo, Japan). The two cameras were chosen as they were considered representative of the range of action cameras (Gopro Hero4) and mirror-less cameras (Sony NEX7) currently available on the market. The proposed methodology was validated with respect to both cameras. Both the Gopro Hero4 and the Sony NEX7 cameras recorded nadiral imagery, at a constant ground sampling distance, along four parallel transects traveling from the deeper to the shallower area of the cliff (Figure 2a). The cameras were placed at a maximal standard distance of $1.5 \mathrm{~m}$ from the substrate and moved along parallel transects.

The Gopro Hero4 had a CMOS sensor and recorded $4000 \times 3000$ pixels images with the imagery being automatically recorded every second. The Sony NEX7, also equipped with a CMOS sensor, recorded in video format at 50 frames per second, with progressive mode and frame size of $1920 \times 1080$ pixels (Figure 3 and Table S1). The cameras were equipped with two RGBlue (AOI Japan Co., Ltd, Yokohama, Japan) System01-2 video LED torches with total luminous flux of $5000 \mathrm{~lm}$.

A total of three 3D ground control points were systematically distributed every three metres along the rocky cliff, from West to East, at $-34 \mathrm{~m}$. The ground control points consisted of plastic tripods with a calibrated chessboard extension (Figures $2 \mathrm{a}$ and 3 ). The dimension of each of the ground control points was $22 \mathrm{~cm} \times 22 \mathrm{~cm} \times 22 \mathrm{~cm}$. The chessboard extension was $21 \mathrm{~cm}$ long by $8 \mathrm{~cm}$ wide. The $52 \mathrm{~m}^{2}$ study site was sampled within six minutes under clear and steady sea water conditions.

\subsubsection{Gorgonian Colony Density and Morphometry Measurement}

In each stratum, the colonies larger than $15 \mathrm{~cm}$ falling within three randomly distributed $1 \mathrm{~m} \times 1 \mathrm{~m}$ quadrats, were counted in-situ. This count data constituted the "abundance" ground-truth dataset (Section 2.4) which was used to validate the SfM-estimated density and abundance (Section 2.5). In each quadrat, two colonies were photographed with a dimensional reference (Figure $2 b$ ) and the morphometries measured by photo analysis. This data represented the "morphometric" ground truth dataset which was used to validate the SfM- estimated colonies morphometries (maximal height, maximal width and fan planar surface) (Section 2.5). The images taken for that purpose were not used in the SfM processing.

\subsubsection{Relationship between Planar Surface Area and Weight}

Nine colonies of various sizes were collected outside of the study area but as close as possible to the Marine Protected Area borders and at the same depth as the study area. The colonies were dried, photographed in a cubelite following the SfM approach (Figures $2 \mathrm{c}$ and S1) and the coenenchymal surface area (A) measured. This constituted the laboratory ground truth and was used to validate the coenenchymal surface estimated through SfM (Section 2.5). 

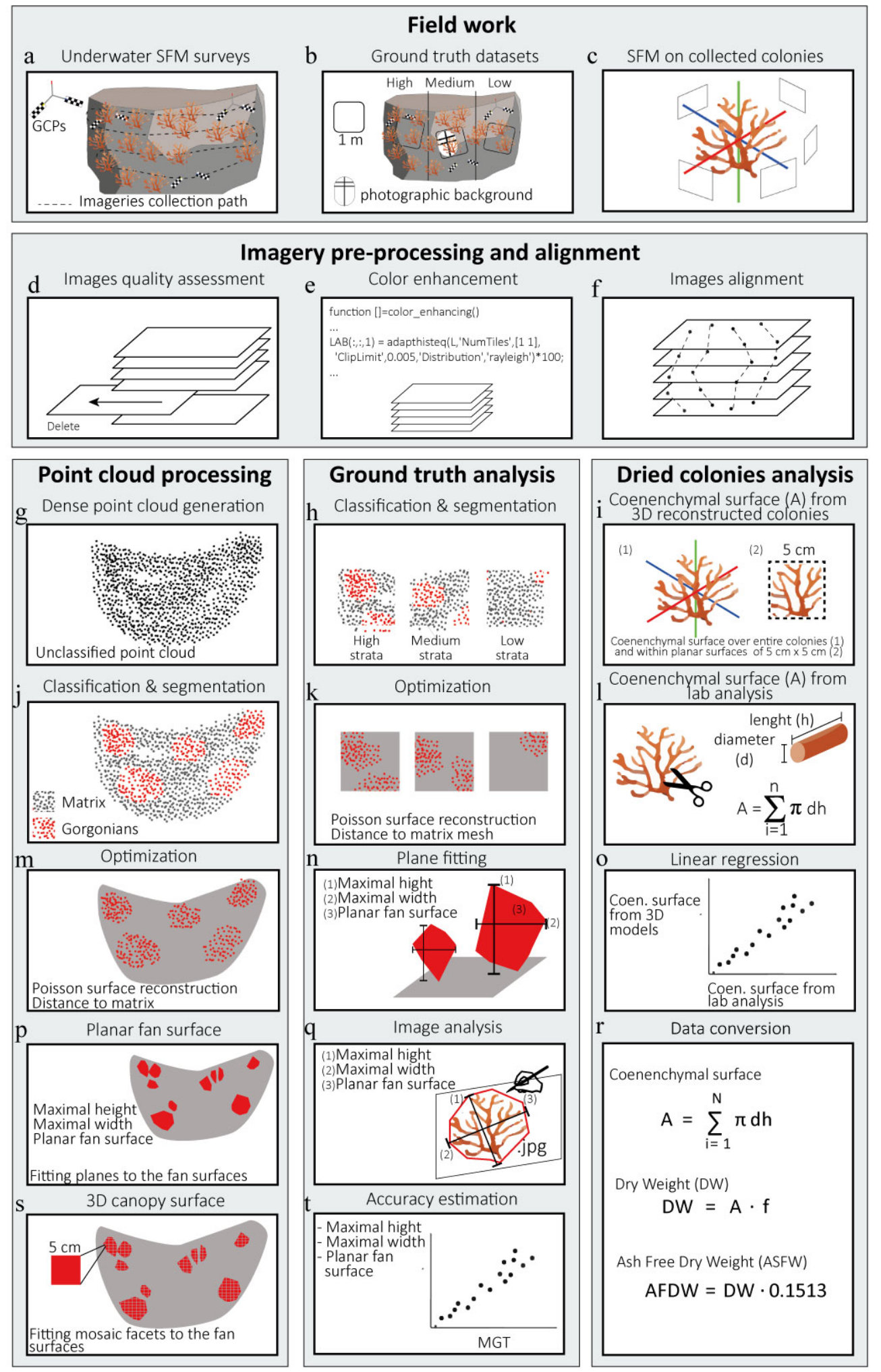

Figure 2. Schematic diagram summarizing the workflow including data collection, imagery pre-processing and alignment, point cloud processing, ground truth data analysis and the analysis of the dried colonies (i.e., biomass). 


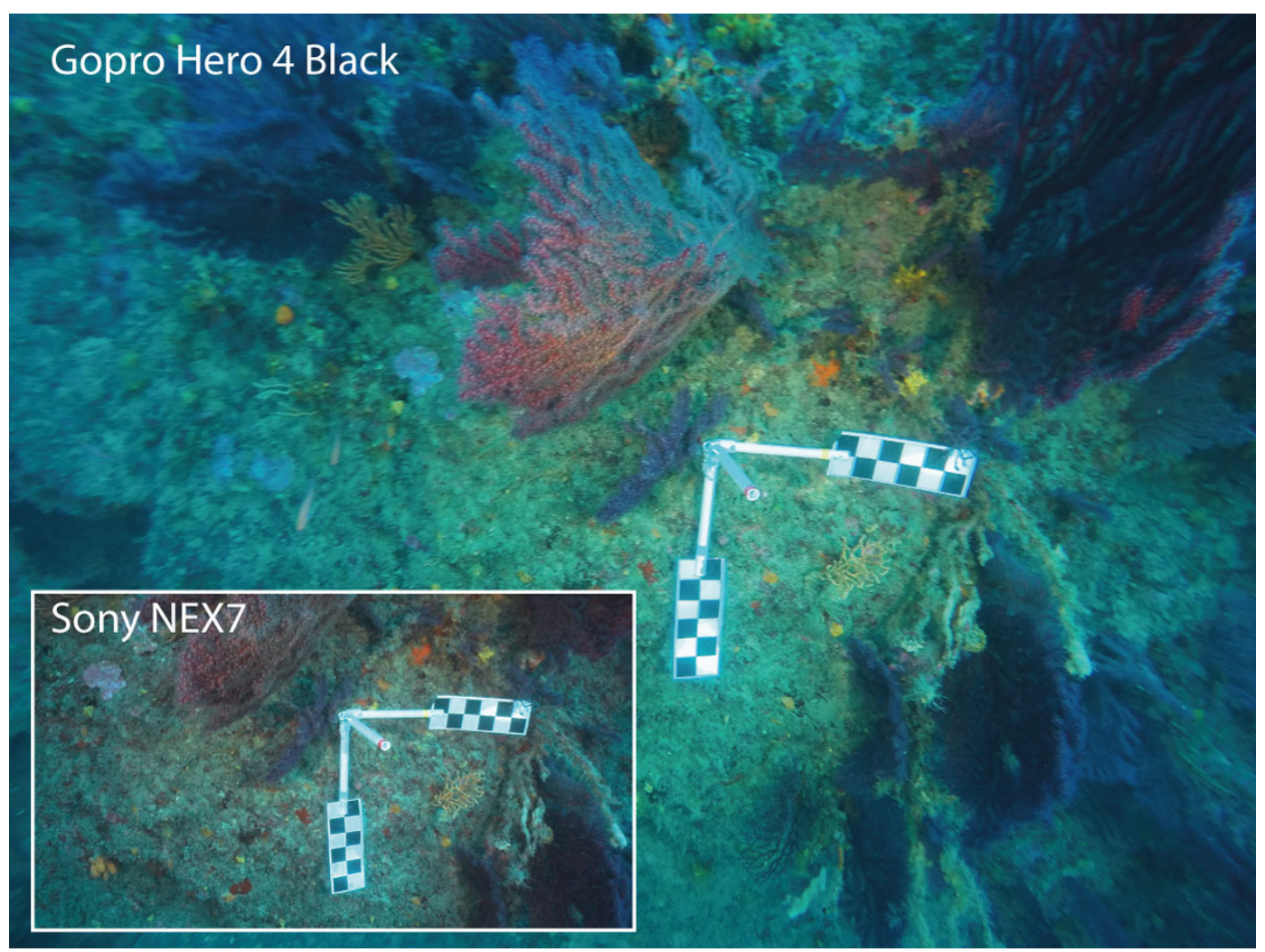

Figure 3. Image footprint obtained with the Gopro Hero4 Black Edition (Woodman Labs, Inc., San Mateo, CA, USA) and the Sony NEX7 alpha (Sony Corporation, Minato, Tokyo, Japan) with both cameras being triggered at the same point over a ground control point. The image depicts the difference in frame size and in extent covered by each frame. The dimension of each of the ground control points was $22 \mathrm{~cm} \times 22 \mathrm{~cm} \times 22 \mathrm{~cm}$. The chessboard extension was $21 \mathrm{~cm}$ long by $8 \mathrm{~cm}$ wide.

The branches were divided into fragments and the height and the diameter of each fragment were measured $[7,40]$. The total $A$ of each colony was estimated as:

$$
A=\pi \sum_{i=1}^{N}\left(d_{\mathrm{i}} h_{\mathrm{i}}\right)
$$

where $i$ is a given fragment from 1 to the total number of segments $(N)$ for the target colony, $d$ is the diameter and $h$ is the length of the fragments. The dry weight $(D W)$ was calculated as the product of $A$ by a conversion factor $(f)$ specific for $P$. clavata [7] (Table 1$)$ :

$$
D W=A \cdot f
$$

where $\mathrm{f}$ is equal to $0.0047 \mathrm{~g} \mathrm{~cm}^{-2}( \pm 0.0020 \mathrm{SD})$.

The ash free dry weight $(A F D W)$ represents the biomass weight remaining after oxidation of the organic component at high temperature.

$$
A F D W=D W \cdot 0.1513
$$

The resulting dry weight and ash free dry weight values per $\mathrm{m}^{2}$ were directly used to derive their content overall to the whole study site $\left(52 \mathrm{~m}^{2}\right)$ and the full extent of the coralligeneous habitat along the Marine Protected Area of Portofino (Punta del Faro, Italy) $\left(86,300 \mathrm{~m}^{2}\right)$ (Figure S2a,b). 
Table 1. Description of the metrics calculated from the Structure from Motion (SfM) based approach presented in this paper. A dash line separator is used for "Maximal height" because it is a metric used both in structural and morphological metric categories.

\begin{tabular}{|c|c|c|c|c|}
\hline Categories & Metrics & Tool & Unit & Description \\
\hline \multirow{2}{*}{ Structural } & Abundance & CloudCompare, Facet & count & Number of colonies within the study area \\
\hline & Density & CloudCompare, Facet & count & Number of colonies per square metre \\
\hline \multirow{5}{*}{ Morphology } & Maximal height & CloudCompare, Facet & $\mathrm{cm}$ & Maximal vertical extension of the segmented colony. \\
\hline & Maximal width & CloudCompare, Facet & $\mathrm{cm}$ & Maximal horizontal extension of the segmented colony. \\
\hline & Planar fan surface & CloudCompare, Facet & $\mathrm{cm}^{2}$ & $\begin{array}{l}\text { Surface of the polygon generated by fitting } \\
\text { a single plane to the colony's point cloud. }\end{array}$ \\
\hline & 3D canopy surface & CloudCompare, Facet & $\mathrm{cm}^{2}$ & $\begin{array}{l}\text { Mosaic of planes generated by fitting } \\
\text { multiple facets dimensioned } 5 \mathrm{~cm} \times 5 \mathrm{~cm} \\
\text { within the point cloud. }\end{array}$ \\
\hline & Coenenchymal surface (A) & $\begin{array}{l}\text { Meshlab, Screened } \\
\text { Poisson Surface } \\
\text { Reconstruction }\end{array}$ & $\mathrm{cm}^{2}$ & $\begin{array}{l}\text { Total tissue surface of the gorgonian calculated } \\
\text { through the generation of the 3D model of the colony. }\end{array}$ \\
\hline \multirow{2}{*}{ Biomass } & Dry weight (DW) & Conversion factor & $\mathrm{g}$ & $\begin{array}{l}\text { Weight of the dry coenenhymal tissue of the } \\
\text { gorgonian estimated through the conversion } \\
\text { from surface unit }\left(\mathrm{cm}^{2}\right) \text { to weight per } \\
\text { surface unit }\left(\mathrm{g} \mathrm{cm}^{-2}\right)[7]\end{array}$ \\
\hline & Ash Fee Dry Weight (AFDW) & Conversion factor & $\mathrm{g}$ & $\begin{array}{l}\text { Weight of the inorganic component of the } \\
\text { coenenchymal tissue estimated through } \\
\text { the conversion from DW (g) to Ash Free } \\
\text { Dry Weight (AFDW) (g) [7] }\end{array}$ \\
\hline
\end{tabular}

\subsection{Image Processing}

All the imagery collected underwater was screened and chosen for photogrammetric processing when having suitable image quality and consecutive spatial coverage [30] (Figure $2 \mathrm{~d}-\mathrm{f}$ and Table 2). The selected images were processed within Matlab (Mathworks, Natick, MA, USA) using the Contrast Limited Adaptive Histogram Equalization (CLAHE) algorithm [41] to enhance the luminosity, sharpness and contrast of the images (Figure 2e). The uncalibrated images were then processed using AgiSoft Photoscan software (Agisoft LLC., St. Petersburg, Russia) to estimate the relative camera poses and generate dense clouds.

For consistency and comparability purposes, both Gopro Hero4 and Sony NEX7 datasets were aligned together generating a sparse point cloud and then separated to create the dense point cloud under the same settings (Figure 2f). The photogrammetric processing was performed with an Asus laptop (Beitou District, Taipei, Taiwan) with an Intel Core i7-3630QM 2.40-GPz processor (Intel Corporation, Santa Clara, CA, USA), 16 Gb RAM and NVIDIA Geoforce GTX 670M (NVIDIA Corporation, Santa Clara, CA, USA) graphic card. The overall procedure for the two cameras combined required a total of $10 \mathrm{~h}$ (Figure 2g). The resulting dense point clouds were sub-sampled at $1 \mathrm{~mm}$, scaled using the ground control point and cleaned of extremes and outliers using the software CloudCompare [42]. Then, the clouds were clipped using a polygon mask to a common surface of $52 \mathrm{~m}^{2}$.

The dense point clouds (and derived population structure and morphometry) obtained by processing the imagery of each camera, were compared to determine the sensitivity of the proposed SfM method to the equipment used. For that purpose, the closest point distance between the two clouds was calculated. For each point of the second point cloud, the closest point from the first point cloud and the distance between them was recorded [43]. Similarly, the point frequency per distance class $(1 \mathrm{~cm})$ and the average value were also calculated. The imagery collected in the cubelite from the dried colonies was also processed to generate dense point clouds. The Screened Poisson Reconstruction filter in Meshlab, ref. [44] was applied to the cleaned and scaled dense point cloud to generate an accurate coenenchymal surface model of each colony (Figures $2 i$ and 4 ). 

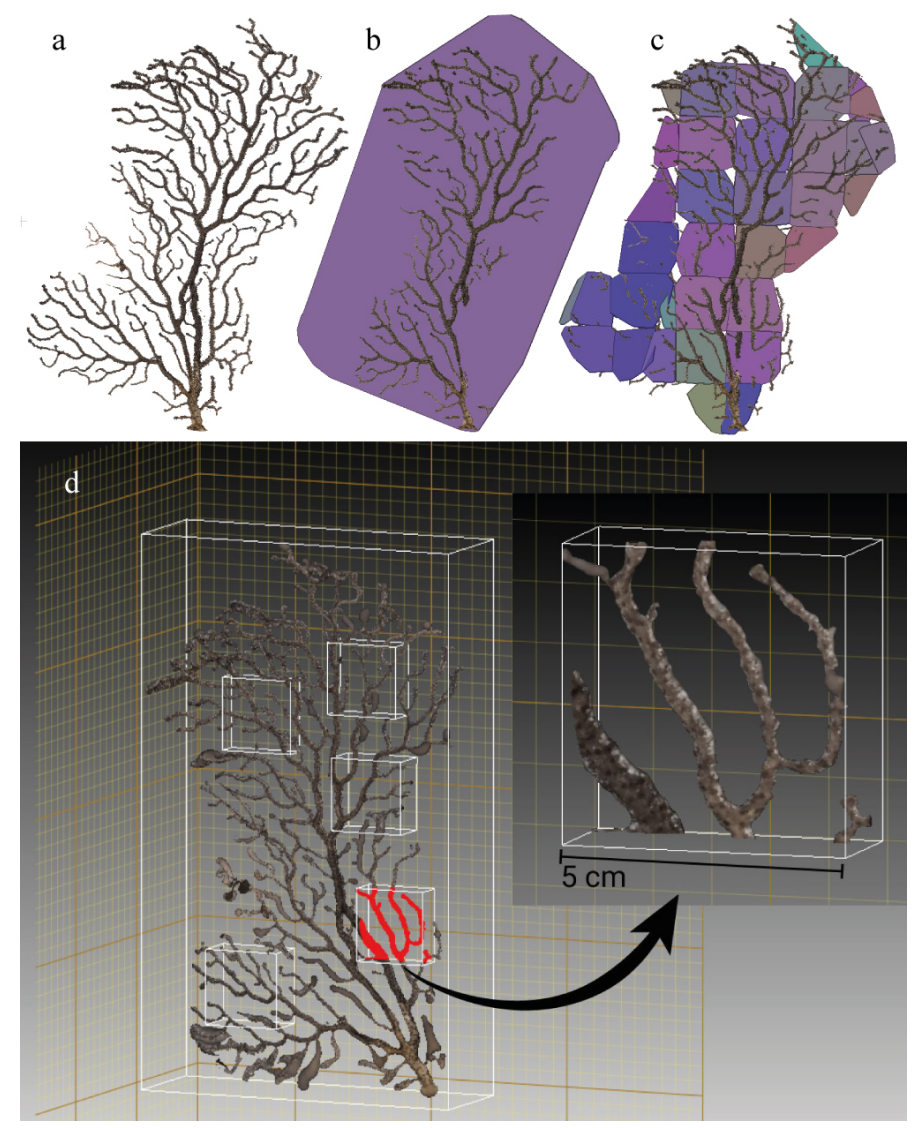

Figure 4. (a) the point cloud generated from SfM on one of the dried colonies; (b) the planar fan surface interpolated over the colony; (c) the mosaic of planes representing the filtering gorgonian surface; (d) the 3D reconstruction of the colony's coenenchymal surface with the detail of one quadrat sample of $5 \mathrm{~cm} \times 5 \mathrm{~cm}$.

Table 2. Summary of key image processing outcomes using the Gopro Hero4 Black Edition (GP) and the Sony NEX7 alpha (SN).

\begin{tabular}{lcc}
\hline & GP & SN \\
\hline Number of collected images & 365 & 333 \\
Number of processed images & 325 & 321 \\
Processing time (h) & 5 & 5 \\
Colonies detected & 103 & 71 \\
Point cloud density $\left({\text { pts } \mathrm{m}^{-2} \text { ) }}^{-120,442}\right.$ & 209,269 \\
Nominal pixel dimension $(\mathrm{mm})$ & 0.558 & 0.741 \\
\hline
\end{tabular}

\subsection{Data Analysis}

\subsubsection{SfM Estimation of Gorgonian Density Colony and Morphometry}

Classification and segmentation techniques were used to estimate the population structure (density, maximal height ) and morphometries (maximal height, maximal width, planar fan surface, 3D canopy surface) (Table 1). These methods were applied to the generated point clouds to distinguish the background matrix and the gorgonians point clouds. The classification was performed using the CANUPO classifier [45] available as a plugin for CloudCompare [42], with the algorithms trained through the manual selection of points that represented both the "matrix" and the "gorgonian" classes (Figure 2h,j). 
The classifier used a multi-scale calculation around each point analysing the 1D (points set along a line), 2D (points forming a plane) and 3D (volume relation) between each point within the cloud (Figure 2h,j). The segmentation of the "gorgonian" point cloud was carried out in Meshlab [46] directly after classification by selecting and deleting from the unclassified point cloud, all the points closer than $5 \mathrm{~cm}$ to the mesh fused from the "matrix" point cloud (Figures $2 \mathrm{~m}$ and $5 \mathrm{a}, \mathrm{b}$ ). Colony abundance, density and morphometries were calculated from the "gorgonian" point cloud using the Facet Plugin [47] of CloudCompare [42]. This plugin, developed to study the geological planar facets (Figure 4) of rock out-crops, processed the point cloud twice. The first time, to count the gorgonian's fans by approximating them to elementary planar objects (Figures $2 p$ and $5 c$ ) and to calculate the maximal height, maximal width and planar fan surface (Table 1). The second time, to divide the point cloud into a mosaic of facets with maximal dimension of $5 \mathrm{~cm} \times 5 \mathrm{~cm}$ (Figure 2s) from which the 3D canopy surface (Table 1, Figures $4 \mathrm{c}$ and $5 \mathrm{~d}$ ) of the population was estimated as the sum of the individual facet surfaces.The facet dimensions $(5 \mathrm{~cm} \times 5 \mathrm{~cm})$ were determined based on the size of the smallest colonies considered in the study site.
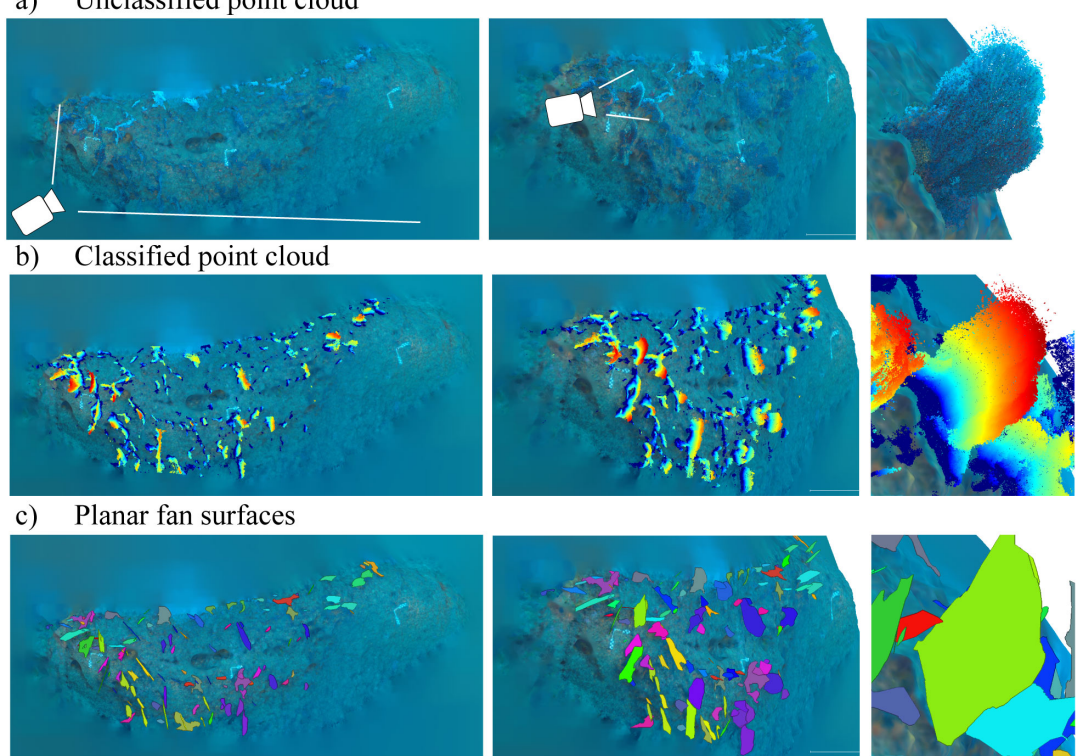

d) 3D canopy surfaces
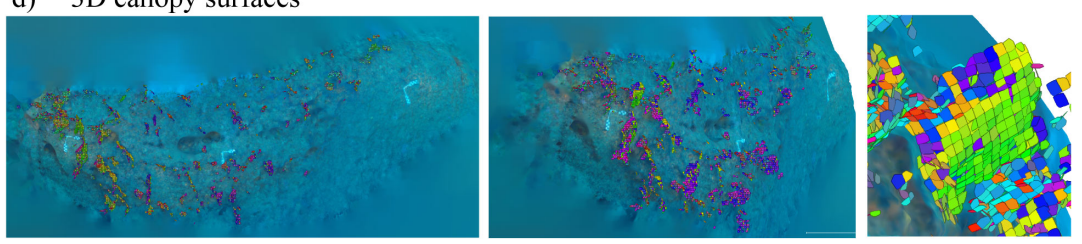

Figure 5. Three spatial representations of: (a) The unclassified point cloud (blue); (b) the point cloud segmented into matrix (blue background) and gorgonians (other colours); (c) the planar surfaces fitted to the point cloud and representing the colonies (matrix in blue and gorgonians in multiple colours); (d) the 3D canopy surface generated by fitting facets with a maximal dimension of $5 \mathrm{~cm} \times 5 \mathrm{~cm}$ to the point cloud. The three spatial representations include (from left to right): the orthoimage, a prospective view from the Western point of the case study area and a close-up view of a gorgonian.

\subsubsection{Dried Colonies Analysis}

The morphometries of the morphological ground truth dataset and of the dried colonies, with the exception for the filtering fan surface, were estimated from the images collected with the dimensional reference (Figure 2q) and manually measured using the software ImageJ [48]. The coenenchymal surface area (A) was calculated as the sum of the surface area within each facet composing the 3D canopy surface. 
Within each facet, the average coenenchymal surface area was obtained from the nine dried colonies 3D-reconstructed that were randomly sampled using 56 quadrats $(5 \mathrm{~cm} \times 5 \mathrm{~cm})$ (Figure 2i). According to the colony size, the sampling was replicated from three to nine times. The coenenchymal surface was then computed using the geometry filter in Meshlab software (Figure 4). The average colonies DW and the average AFDW were estimated using Equations (2) and (5).

\subsection{Validation}

Colony density and abundance estimated by the SfM were compared against the abundance ground truth dataset by counting the identified colonies within the $1 \mathrm{~m} \times 1 \mathrm{~m}$ quadrats across the three density strata. The SfM-estimated morphometries were validated against the morphological ground truth dataset and a linear regression model performed to assess the accuracy of morphometries estimation (Figure 2t). The SfM-estimated coenenchymal surface estimation (A) was compared against the laboratory ground truth dataset and its accuracy calculated by applying a linear regression model. A residual analysis was carried out for all linear regression models to assess the validity of the normality, homoscedasticity and independence assumptions (Figure 2o).

\section{Results}

A total of 325 and 321 images were processed respectively by the Gopro Hero4 and Sony NEX7 cameras. Tables 2 and S2 summarize the total number of frames included in the photogrammetric processing pipeline. The point clouds generated over the study area contained 10.9 million and 6.2 million points each and the cloud to cloud distance was on average $3 \mathrm{~cm} \pm 1.8 \mathrm{SD}$. Over $98 \%$ of the points presented a cloud to cloud distance smaller than $8 \mathrm{~cm}$ with an average distance between the two point clouds representing the gorgonians of $1.6 \mathrm{~cm} \pm 5.3 \mathrm{SD}$.

\subsection{SfM-Population Structure Estimates and Validation}

The gorgonian population had a mean density of 12.4 colonies $\mathrm{m}^{-2}$ (Table 3 , pilot study). The densities ranged between 6.4 colonies $\mathrm{m}^{-2}$ to 16.8 colonies $\mathrm{m}^{-2}$ across the three strata (Table 3 ). The species distribution was denser along the Western side of the cliff and sparser towards the Eastern side. The SfM estimated higher abundance of $P$. clavata using the Gopro Hero4 (103 colonies) than the Sony NEX7 camera (71 colonies) (Table 2). The density estimated by SfM-method ranged between 3.3 colonies $\mathrm{m}^{-2}$ to 14.0 colonies $\mathrm{m}^{-2}$ across the three strata (Table 3 ). The Gopro Hero4 showed higher accuracies (89\%, 81\%, 100\% in high, medium and low density strata respectively) than the Sony NEX7 camera $(60 \%, 71 \%, 77 \%$ in high, medium and low density strata respectively) across strata (Figure S2). When compared to the abundance ground truth dataset, the SfM-density estimates demonstrated an overall systematical underestimation for both cameras and across strata. The Gopro Hero4 showed lower departures from the abundance ground truth dataset values, $<2.0$ colonies $\mathrm{m}^{-2}$, whereas the Sony NEX7 camera presented larger departures, $<6.4$ colonies $\mathrm{m}^{-2}$ (Table 3).

Table 3. Mean gorgonian density (colonies $\mathrm{m}^{-2}$ ), density range (minimum to maximum in number of colonies per quadrat) and abundance (number of colonies) within each stratum in the study area. Note that all the quadrats are $1 \mathrm{~m} \times 1 \mathrm{~m}$, except for the pilot study where the quadrats are $0.5 \mathrm{~m} \times 0.5 \mathrm{~m}$. Values in brackets denote the standard deviation. SfM stands for Structure from Motion. GP and SN stand for Gopro Hero4 and Sony NEX7, respectively. AGT stands for abundance ground truth dataset.

\begin{tabular}{llccc}
\hline & Metrics & High Density & Strata Medium Density & Low Density \\
\hline Pilot study $0.5 \mathrm{~m} \times 0.5 \mathrm{~m}$ & Average Range & $16.8( \pm 7.6) 1-7$ & $14.0( \pm 4.0) 1-4$ & $6.4( \pm 9.2)-3$ \\
AGT $1 \mathrm{~m} \times 1 \mathrm{~m}$ & Average Range & $15.7( \pm 1.9) 13-17$ & $10.3( \pm 1.2) 7-12$ & $4.3( \pm 1.2) 3-6$ \\
SfM-GP $1 \mathrm{~m} \times 1 \mathrm{~m}$ & Average Range & $14.0( \pm 1.4) 13-16$ & $8.3( \pm 0.9) 7-9$ & $4.3( \pm 1.2) 3-6$ \\
SfM-SN $1 \mathrm{~m} \times 1 \mathrm{~m}$ & Average Range & $9.3( \pm 1.2) 8-11$ & $7.3( \pm 2.1) 5-10$ & $3.3( \pm 0.5) 3-4$ \\
\hline
\end{tabular}


The study site was dominated by colonies of small/ medium sizes (Figure 6). The colonies recorded by the Gopro Hero4 and the Sony NEX7 cameras ranged between 10-58 cm in maximal height, $7-55 \mathrm{~cm}$ in maximal width and $60-1770 \mathrm{~cm}^{2}$ in planar surface (Table 5). The comparison of the SfM estimates with the morphological ground truth dataset values showed that both cameras underestimated maximal height measures by $2.6 \mathrm{~cm}$ (Gopro Hero4) and $1.9 \mathrm{~cm}$ (Sony NEX7). The difference between the morphological ground truth dataset and the SfM cameras ranged between $-11.1 \mathrm{~cm}$ and $12.6 \mathrm{~cm}$ for the Gopro Hero4 and between $-7.9 \mathrm{~cm}$ and $9.1 \mathrm{~cm}$ for the Sony NEX7, where negative values indicated underestimation. The mean maximal width was also underestimated by $3.6 \mathrm{~cm}$ (Gopro Hero4) and $2.5 \mathrm{~cm}$ (Sony NEX7). The difference between the morphological ground truth and the SfM estimates ranged from $-9.2 \mathrm{~cm}$ to $13.0 \mathrm{~cm}$ (Gopro Hero4) and $-14.7 \mathrm{~cm}$ and $14.7 \mathrm{~cm}$ (Sony NEX7).
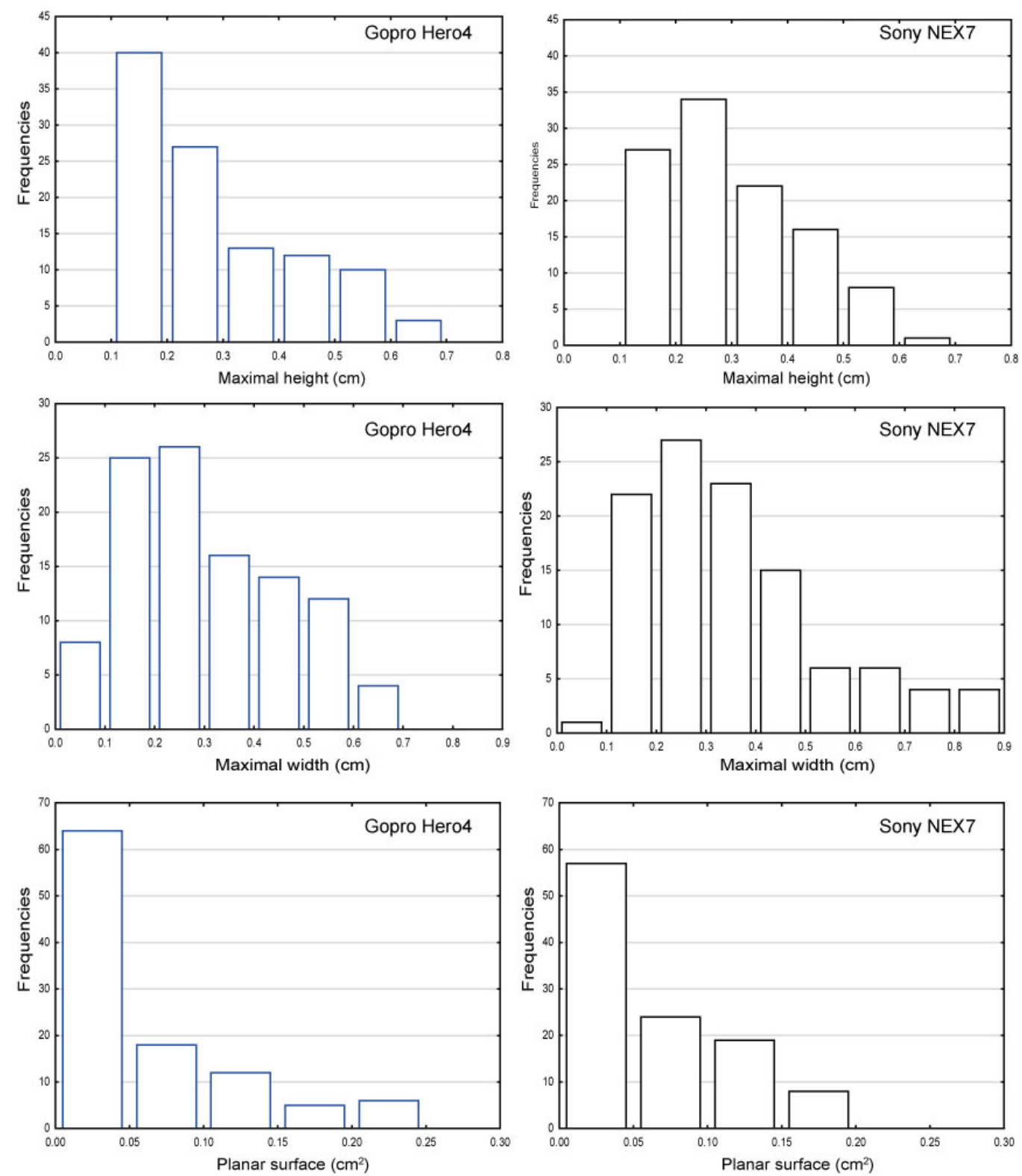

Figure 6. Histogram of the morphometric values obtained for the SfM method across the study site of Punta del Faro (Portofino, Italy). 
The value for the mean planar fan surface was underestimated by $153 \mathrm{~cm}^{2}$ (Gopro Hero4) and $53 \mathrm{~cm}^{2}$ (Sony NEX7). The difference between the morphological ground truth and the cameras ranged between $-276 \mathrm{~cm}^{2}$ and $533 \mathrm{~cm}^{2}$ (Gopro Hero4) and $-552 \mathrm{~cm}^{2}$ and $420 \mathrm{~cm}^{2}$ (Sony NEX7). Finally, the results of the linear regression analysis between the estimated SfM morphometric and the morphological ground truth showed that the Gopro Hero4 camera was more accurate than the Sony NEX7 in estimating the maximal width and planar fan surface $\left(R^{2}=0.8, R^{2}=0.9\right)$ whereas the Sony NEX7 provided better estimations of maximal height measures $\left(R^{2}=0.8\right)$ (Figure 7).
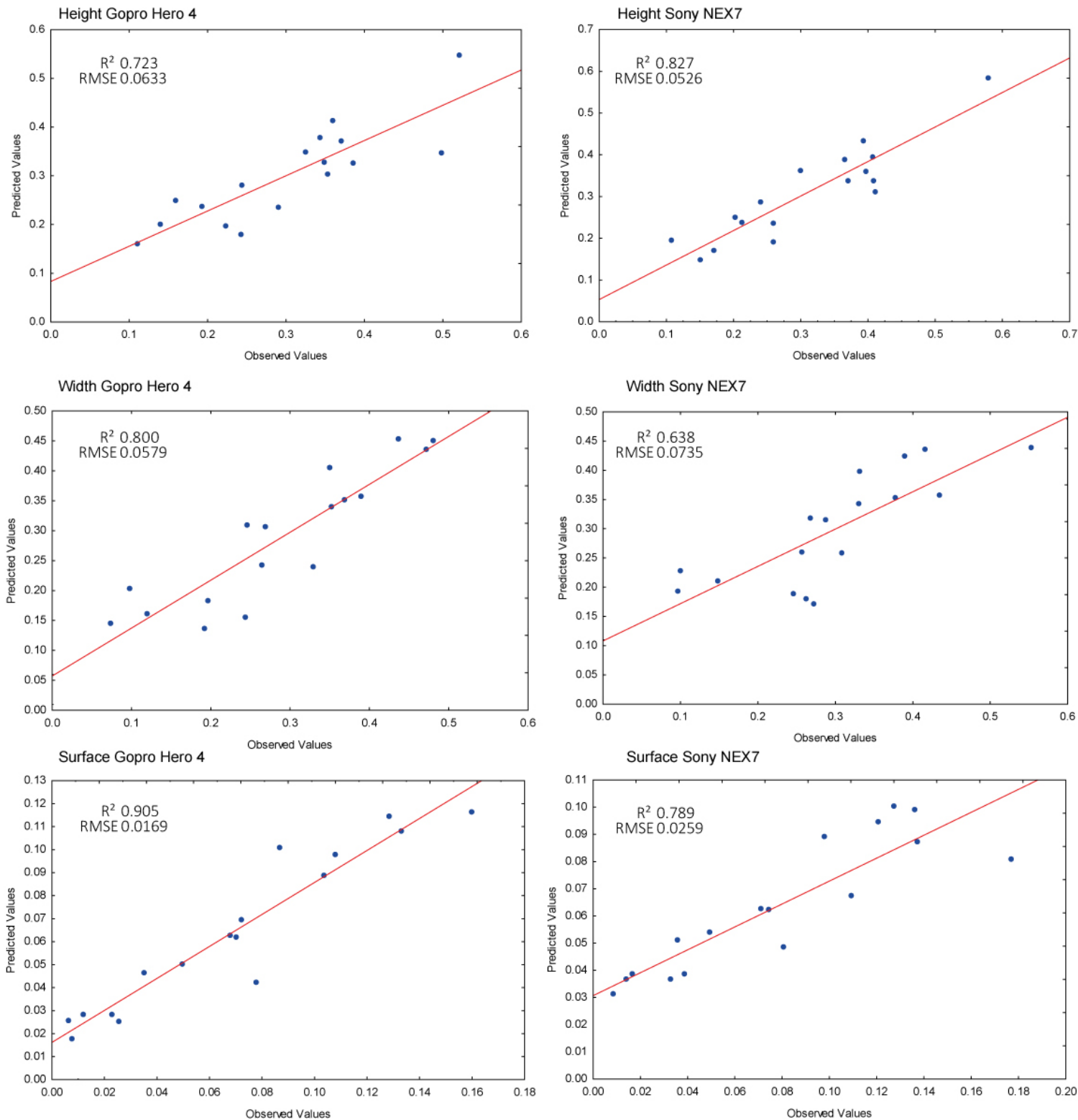

Figure 7. Correlation between the SfM method vs. the ground truth data for each of the morphometrics calculated and cameras considered: (a) Gopro Hero4 and (b) Sony NEX7. Height refers to maximal height $(\mathrm{m})$, width refers to maximal width $(\mathrm{m})$ and surface refers to planar fan surface area $\left(\mathrm{m}^{2}\right)$. 


\subsection{SfM-Biomass Estimation and Validation}

The mean coenenchymal surface obtained from the 56 sampling quadrats $(5 \mathrm{~cm} \times 5 \mathrm{~cm})$ was $23.24 \mathrm{~cm}^{2}( \pm 0.06 \mathrm{SD})$ and corresponded to a coenenchymal dry weight of $0.109 \mathrm{~g}( \pm 0.0750 \mathrm{SD})$ per facet. The total coenenchymal surface, derived from the 3D canopy surface estimated across the study site, was $4.74 \mathrm{~m}^{2}$ (Gopro Hero4) corresponding to 1896 facets and $4.61 \mathrm{~m}^{2}$ (Sony NEX7) for a total of 1844 facets (Figure 5d). Lower estimates of 3D canopy surface were obtained with the Sony NEX7.

The linear regression analysis showed a strong correlation between the laboratory ground truth dataset and SfM $R^{2}=0.99$ (Figure 8). SfM overestimated the calculation of the coenenchymal surface (Table 4): the differences with respect to the laboratory ground truth dataset varied between $24.6 \mathrm{~cm}^{2}$ and $341.2 \mathrm{~cm}^{2}$. The nine colonies used for dry weight estimation showed sizes comprised between the small colonies dimensions (15.1 maximal height, $9.9 \mathrm{~cm}$ maximal width, $115.6 \mathrm{~cm}^{2}$ planar fan surface) to the big dimensions ( $55.6 \mathrm{~cm}$ in maximal height, $30.3 \mathrm{~cm}$ maximal width, $729.8 \mathrm{~cm}^{2}$ planar fan surface) (Table 5).

The dry weight values calculated from the coenenchymal surfaces, are reported in Table 4 . For the laboratory analysis, the mean dry weight content per colony corresponded to $1.56 \mathrm{~g}$, whereas for the $\mathrm{SfM}$ method the value was $2.27 \mathrm{~g}$. The calculated mean adh free dry weight did not differ by more than 0.24 g per colony between the two methods.

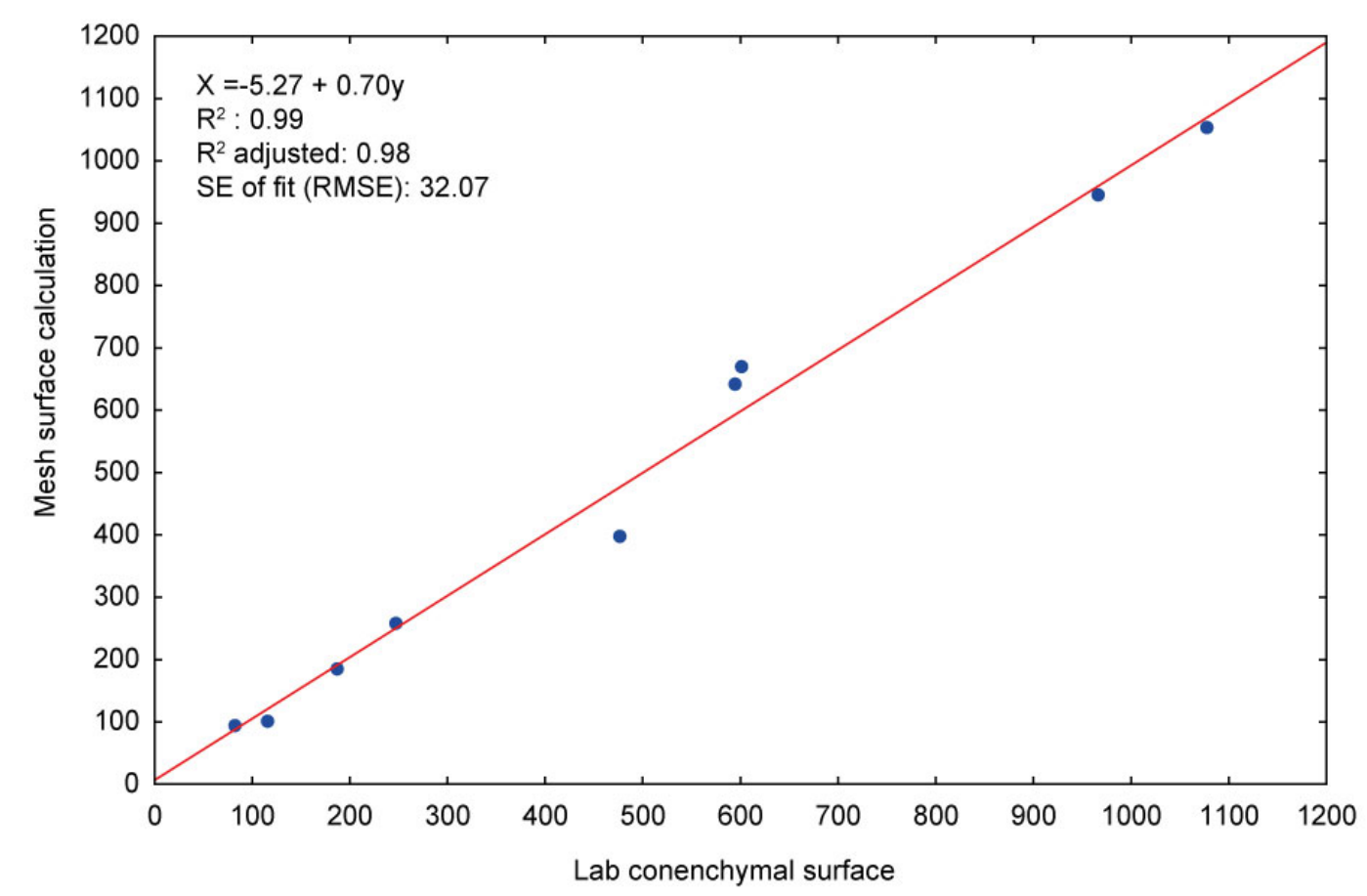

Figure 8. Correlation between the coenenchymal surface estimated through the SfM method and the laboratory measurements over the nine dried gorgonian colonies. 
Table 4. Summary of morphometric results for the study site. The abbreviations used correspond to: Structure-from-Motion (SfM), laboratory (lab), coenenchymal (coen), Dry Weight (DW) based on [25], Ash Free Dry Weight (AFDW) and difference (diff). Positive differences represent overestimations.

\begin{tabular}{|c|c|c|c|c|c|c|c|c|c|c|}
\hline Colonies & Units & 1 & 2 & 3 & 4 & 5 & 6 & 7 & 8 & 9 \\
\hline Maximal height & & 24.43 & 15.07 & 39.31 & 19.78 & 24.12 & 24.56 & 38.09 & 55.65 & 38.26 \\
\hline Maximal width & & 12.82 & 11.53 & 21.49 & 9.89 & 16.02 & 20.30 & 30.33 & 15.74 & 22.63 \\
\hline Fan surface & $\mathrm{cm}^{2}$ & 196.95 & 115.66 & 667.76 & 124.05 & 226.10 & 428.86 & 729.88 & 609.41 & 566.55 \\
\hline \multirow{3}{*}{$\begin{array}{l}\text { Coen. surface SfM analysis } \\
\text { Coen. surface lab analysis } \\
\text { Diff. between SfM and } \\
\text { lab coen surfaces }\end{array}$} & \multirow{3}{*}{$\mathrm{cm}^{2}$} & 186.48 & 82.72 & 600.56 & 115.57 & 246.48 & 475.77 & 966.34 & 1078.17 & 601.43 \\
\hline & & 121.30 & 58.13 & 465.82 & 61.98 & 172.88 & 273.61 & 660.46 & 736.99 & 445.65 \\
\hline & & 65.18 & 24.59 & 134.76 & 53.59 & 73.6 & 202.16 & 305.88 & 341.18 & 149.78 \\
\hline \multirow{3}{*}{$\begin{array}{l}\text { Coen. DW SfM analysis } \\
\text { Coen. DW lab analysis } \\
\text { Diff. between SfM and } \\
\text { lab DW }\end{array}$} & \multirow{3}{*}{$\mathrm{g}$} & 0.876 & 0.388 & 2.822 & 0.543 & 1.158 & 2.236 & 4.541 & 5.067 & 2.798 \\
\hline & & 0.570 & 0.273 & 2.189 & 0.291 & 0.812 & 1.285 & 3.104 & 3.463 & 2.094 \\
\hline & & 0.306 & 0.115 & 0.633 & 0.252 & 0.346 & 0.951 & 1.437 & 1.604 & 0.704 \\
\hline \multirow{3}{*}{$\begin{array}{l}\text { AFDW SfM analysis } \\
\text { AFDW lab analysis } \\
\text { Diff. between SfM and } \\
\text { lab AFDW }\end{array}$} & \multirow{3}{*}{$g$} & 0.133 & 0.059 & 0.427 & 0.082 & 0.175 & 0.338 & 0.687 & 0.767 & 0.423 \\
\hline & & 0.086 & 0.041 & 0.331 & 0.044 & 0.123 & 0.194 & 0.470 & 0.524 & 0.317 \\
\hline & & 0.046 & 0.017 & 0.096 & 0.038 & 0.052 & 0.144 & 0.217 & 0.243 & 0.107 \\
\hline
\end{tabular}


Table 5. Mean and range of the estimated morphometrics for the colonies sampled in-situ with a dimensional background for each of the approaches considered. Height and width stand for maximal height and maximal width, respectively. $\mathrm{N}$ stands for the number of colonies used for the morphometric estimation. MGT stands for Morphometry Ground Truth data set. Within the table, difference refers to the difference between MGT and SfM outcomes. Positive differences represent overestimations.

\begin{tabular}{ccccccc}
\hline Study & Metric & N & Mean & Range & $\begin{array}{c}\text { Mean } \\
\text { Difference }\end{array}$ & $\begin{array}{c}\text { Difference } \\
\text { Range }\end{array}$ \\
\hline MGT & & 17 & 32.63 & $14.3-64.7$ & - & - \\
SfM-GP & Height $(\mathrm{cm})$ & 17 & 30.0 & $11.1-52.1$ & -2.63 & $-11.12-12.57$ \\
SfM-SN & 17 & 30.7 & $10.7-57.8$ & -1.93 & $-7.95-9.09$ \\
Dry colony analysis & & 9 & 30.6 & $15.1-55.6$ & - & - \\
\hline MGT & & 17 & 32.3 & $12.5-54.3$ & - & - \\
SfM-GP & Width $(\mathrm{cm})$ & 17 & 28.7 & $7.3-48.1$ & -3.63 & $-9.20-13.04$ \\
SfM-SN & & 17 & 29.8 & $9.7-55.2$ & -2.47 & $-14.70-14.69$ \\
Dry colony analysis & & 9 & 18.9 & $9.89-30.3$ & - & - \\
\hline MGT & & 17 & 833 & $120-1640$ & - & - \\
SfM-GP & & 17 & 680 & $60-1590$ & -153.0 & $-276.4-533.0$ \\
SfM-SN & Plannar fan surface $\left(\mathrm{cm}^{2}\right)$ & 17 & 780 & $80-1770$ & -52.8 & $-552.2-420.4$ \\
Dry colony analysis & & 9 & 330 & $116-730$ & - & - \\
\hline
\end{tabular}

\section{Discussion}

The SfM method was developed and applied to P. clavata to showcase the direct estimation of population and colony metrics at a large scale. The comparison between both cameras showed high to moderate accuracy between results and ground-truth data, thus supporting the suitability of the presented method for the estimation of the gorgonian metrics by the SfM data processing. A good agreement between Gopro Hero4 and Sony NEX7 (30\% approximately as per Table 4) was also observed for dry weight and ash free dry weight, thus indicating that the SfM method can be a suitable tool for estimating the indirect contribution of $P$. clavata to local and regional carbon budgets. In this section we discuss the results of the SfM framework on the estimation of P. clavata metrics (Section 4.1) and the domain of application of the method (Section 4.2).

\subsection{Estimated Metrics of P. clavata}

The SfM method (Figure 6) showed promising results when estimating P. clavata population structure, colonies morphometries and biomass suggesting that the method would be transferable for application on similar erected, plane shaped corals. Across all the sampled quadrats and strata, the accuracy on mean colonies density was greater or equal to $60 \%$. The two cameras performed differently on estimating the morphometries although both showed good to moderate agreement with the morphological ground truth data. The error reported for these metrics accounted for the arbitrary decision on the selection of a $5 \mathrm{~cm}$ threshold to segment the "gorgonian" point cloud from the "matrix" point cloud. Lower errors would be expected for a more refined estimation of such a threshold.

The Gopro Hero4 showed higher accuracy than the Sony NEX7 for abundance and density, maximal width and planar fan surface. These results could be explained by the small frame dimension provided by the Sony NEX7 camera when in recording mode (Figure 3 and Table S1), which resulted in clouds with lower number of points. The use of the Sony NEX7 in video recording mode was obliged to ensure an automatic and continuous imagery collection and effective data sampling. The accuracy of the overall method could be improved through the use of cameras in video recording mode that allow for the extraction of frames at frequencies higher than those here presented. The approach will however be limited by the size of the video imagery files collected.

The SfM method allowed for the calculation of the gorgonian planar fan surface based on the planar shape of the gorgonian point cloud. This approach presents an advantage over traditional methods, which usually rely on the product between the maximal height and the maximal width of the colony [26]. In this study, we estimated the Paramuricea clavata 3D canopy surface using SfM; 
this is a novel approach that for the first time provides accurate approximation of the gorgonian population surface by interpolating the species point cloud with a mosaic facets of standard maximal dimension $(5 \mathrm{~cm} \times 5 \mathrm{~cm})$. The metric provides complementary information to those traditionally used in gorgonian population structure studies (i.e., abundance, density, maximal height, maximal width, fan surface) and further insights about the characteristics of the entire population. The accuracy of the coenenchymal surface achieved by the SfM method and validated through the laboratory analysis was promising, supporting the use of virtual sampling for calculating the colony geometry. The calculations are subject to the inherent error associated with water loss of the interbranches fan surface when drying the individual gorgonian samples. Further research should focus on increasing the accuracy of the proposed method by taking into account the loss in volume of the tissues between coral arms.

The average coenenchymal surface per surface unit was converted into DW and AFDW to obtain the biomass of the gorgonian population in the study area. The two cameras showed similar results (223 $\mathrm{g}$ for the Gopro Hero4 and $217 \mathrm{~g}$ for the Sony NEX7), this suggesting that biomass estimation is not affected by the camera characteristics and that the Gopro Hero4 and the Sony NEX7 have similar performances in the estimation of the 3D canopy surface.

The SfM method described a mixed-size gorgonian population; few big colonies (maximal height $>40 \mathrm{~cm}$ ), indicative of greater reproductive organisms, were depicted by both cameras whereas the higher frequencies were identified around small/medium size colonies (maximal height $<30 \mathrm{~cm}$ ). These results are indicative of populations that are recovering after mass mortality events. Similar findings were reported by previous studies on $P$. clavata population structure that have observed an unimodal and bell-shaped distribution of species size in years following mortality episodes [20,49,50]. The Sony NEX7 showed higher frequencies for the wider colonies classes (from $50 \mathrm{~cm}$ to $90 \mathrm{~cm}$ in maximal width) with respect to the smaller number of colonies counted. Regarding the laboratory analysis, the SfM method overestimated the size of the colonies (discrepancy range $24.6-341.2 \mathrm{~cm}^{2}$ ) probably in return of the lower accuracy showed in abundance ground truth dataset comparison.

Finally, field SfM sampling required less than $6 \mathrm{~m}$ for data collection including deployment and retrieval of ground control points, thus ensuring safe scuba diving condition and high-quality data. The sampling approach did not require the manipulation of gorgonians, thus minimizing the risk of seabed contact and as a consequence damage to other benthic organisms [51]. The time required for images alignment was $<5 \mathrm{~h}$ whereas only $4 \mathrm{~h}$ of post-processing time were required to extract the morphometry values. Overall, the operational times were suitable for a fast estimation of the required values, with the times provided improving as the user gets acquainted with data and software manipulation.

Although the point clouds generated with the imagery from both cameras were highly dense (over 6 million points) and only differed an average distance of $1.6 \mathrm{~cm}( \pm 5.3 \mathrm{~cm} \mathrm{SD})$ for the points representing the gorgonians. This discrepancy propagated in the calculation of the population structure and morphometries. The uncertainties associated to the species population structure and morphometry likely affected the estimation of the biomass (dry weight and ash free dry weight). Overall, the SfM framework can provide accuracies suitable for traditional population structure, morphometric and biomass studies [49,52], and is flexible to support finer gorgonian measurements based on the projection of images over point cloud fitted planes [53].

\subsection{Domain of Application}

This study proposes a SfM-based method which allows the estimation of gorgonian population structure, morphometries and biomass, and supports scientist and marine managers in fulfilling the requirements of national and European policies [54,55] on ecosystem functioning assessments (i.e., Environmental accounting). P. clavata was chosen as the species because of its role in structuring the coralligenous habitat and being an indicator of climate change effect, thus an assessment of its conservation status and its contribution for environmental accounting is of key relevance to managers and scientists alike. Several studies have reported that gorgonian populations, recovering after mass mortalities events, tend to reach a new state of equilibrium with lower density and trophic 
energy [20,49,56,57], this implying that the ecological and the economic value of coralligenous habitat can be negatively affected. In the selected areas across the Portofino MPA (Figure S2), the contribution of $P$. clavata was calculated to be between $370.4 \mathrm{~kg}$ (Gopro Hero4) and $360.5 \mathrm{~kg}$ (Sony NEX7) of DW and $56 \mathrm{~kg}$ and $54 \mathrm{~kg}$ of AFDW, not a negligible contribution in terms of trapped organic matter. As highlighted by studies on ecosystem functions, heterotrophic habitat dominated by corals can contribute to carbon turnover and nutrient recycling [58-60] and our approach provides a way forward towards the accurate estimation of the turned organic carbon by animal forests in the Mediterranean Sea. However, the contribution of the phylum Cnidaria in environmental accounting approaches has not been calculated yet [55,61,62]. Our approach is transferable and can therefore assist scientists and managers by providing a method to quantify the essential gorgonian forest metrics and to prioritize actions over spatial scales relevant for the MPAs management even supporting existing conservation indexes on coralligenous habitat (see Sartoretto et al. [63]). Finally, existing scientific literature suggests that knowing the structure and morphometry at population level is fundamental to assess the conservation status of marine habitats and their ecosystem functions. There is an increasing emphasis on addressing innovative technologies to monitor marine habitats to allow overcoming spatial resolution and temporal data limitations; our SfM framework can support scientists and marine managers as a tool to target key-habitat species and thus provide the greatest benefit to prioritization plans.

\section{Conclusions}

The methodology here presented highlights the potential of SfM based methods for fast and reliable monitoring of demography and morphometry of gorgonian forests. Of particular relevance is the development of the method for very slow growing and threatened species such as gorgonian colonies that are indicators of the effects of climatic anomalies on the coralligeneous community. Results show that the method could complement traditional sampling methods by enabling effective long-frequency wide-area monitoring of gorgonian forests, enhancing current management practices of and compliance with legislative requirements for coralligeneous areas (including MPAs).

Supplementary Materials: The following are available at http:/ /www.mdpi.com/2072-4292/10/7/1154/, Table S1: Camera specifications and settings used for the Gopro Hero4 Black Edition (Woodman Labs, Inc., San Mateo, CA, USA) (GP) and the Sony NEX7 alpha digital (Sony Corporation, Minato, Tokyo, Japan) (SN) cameras used in this study. Table S2: Number of images processed for each of the $1 \mathrm{~m} \times 1 \mathrm{~m}$ quadrats conforming the Abundance Ground Truth (AGT) data set collected with the Gopro Hero4 Black Edition (Woodman Labs, Inc., San Mateo, CA, USA) and the Sony NEX7 alpha digital (Sony Corporation, Minato, Tokyo, Japan) cameras used in this study. Figure S1: The point clouds of the nine dried colonies generated from SfM analysis. Figure S2: Views over the 3D scene representing the study area with the gorgonians fan surfaces generated within the three strata by using the imagery recorded with the Gopro Hero4 Black Edition (Woodman Labs, Inc., San Mateo, CA, USA)(GP) (a,b) and the Sony NEX7 alpha digital (Sony Corporation, Minato, Tokyo, Japan) (SN) (c,d) cameras. Figure S3: The maps showing border of the Portofino Marine Protected Area (Italy) (a), the bathymetries at $20 \mathrm{~m}$ spatial resolution (a), the benthic biocenosis [37] (b), and the selected $8.63 \mathrm{Ha}$ over a total of $22.22 \mathrm{Ha}$ of coralligenous habitats comprised within the depth $-25 \mathrm{~m}$ to $-40 \mathrm{~m}$, considered for the calculation of carbon and Energy contents of the gorgonians' forests living tissues.

Author Contributions: M.P. designed, collected the data, implemented the underwater sampling and process method and wrote the manuscript. M.R.C. supervised the analysis, and contributed to structuring the manuscript. U.P. assisted in the underwater sampling. G.P. contributed in improving the photogrammetric data processing. D.P. assisted with the lab data analysis. C.C. provided guidance on structure, advise and editing for finalizing the manuscript. All authors read and approved the manuscript. The authors have no competing interests to declare.

Funding: This research was funded through the scolarship EUREKA; European Social Funds (FSE), Programma Operativo Regionale (POR) 2014/2020 Regione Marche (Italy) grant number 0020404 and Cranfield University.

Acknowledgments: We thank the Visual Computing Laboratory, Research laboratory of ISTI-CNR (Italy), for providing full support for the development of this research. Special thanks go to Ilaria delle Mura and Fabio Benelli for the underwater support during the surveys and to Carlos Gomez for the photographic support. We also thank the reviewers that helped shape and improve the final version of this manuscript with their useful comments.

Conflicts of Interest: The authors declare no conflict of interest. 


\section{References}

1. Sánchez, J.A. Diversity and evolution of octocoral animal forests at both sides of tropical America. In Marine Animal Forests: The Ecology of Benthic Biodiversity Hotspots; Springer International Publishing: Cham, Switzerland, 2015; pp. 1-33.

2. Ballesteros, E. Mediterranean coralligenous assemblages: A synthesis of present knowledge. Oceanogr. Mar. Biol. Annu. Rev. 2006, 44, 123-195.

3. Rossi, S. The destruction of the 'animal forests' in the oceans: towards an over-simplification of the benthic ecosystems. Ocean Coast. Manag. 2013, 84, 77-85. [CrossRef]

4. Gori, A.; Bavestrello, G.; Grinyó, J.; Dominguez-Carrió, C.; Ambroso, S.; Bo, M. Animal Forests in Deep Coastal Bottoms and Continental Shelf of the Mediterranean Sea. In Marine Animal Forests: The Ecology of Benthic Biodiversity Hotspots; Springer International Publishing: Cham, Switzerland, 2017; pp. 1-27.

5. Valisano, L.; Notari, F.; Mori, M.; Cerrano, C. Temporal variability of sedimentation rates and mobile fauna inside and outside a gorgonian garden. Mar. Ecol. 2016, 37, 1303-1314. [CrossRef]

6. Ponti, M.; Grech, D.; Mori, M.; Perlini, R.A.; Ventra, V.; Panzalis, P.A.; Cerrano, C. The role of gorgonians on the diversity of vagile benthic fauna in Mediterranean rocky habitats. Mar. Biol. 2016, 163, 1-14. [CrossRef]

7. Mistri, M.; Ceccherelli, V.U. Growth and secondary production of the Mediterranean gorgonian Paramuricea clavata. Mar. Ecol. Prog. Ser. 1994, 103, 291-296. [CrossRef]

8. Grigg, R.W. Orientation and growth form of sea fans. Limnol. Oceanogr. 1972, 17, 185-192. [CrossRef]

9. Gili, J.M.; Coma, R. Benthic suspension feeders: Their paramount role in littoral marine food webs. Trends Ecol. Evolut. 1998, 13, 316-321. [CrossRef]

10. Previati, M.; Scinto, A.; Cerrano, C.; Osinga, R. Oxygen consumption in Mediterranean octocorals under different temperatures. J. Exp. Mar. Biol. Ecol. 2010, 390, 39-48. [CrossRef]

11. Vezzulli, L.; Colwell, R.R.; Pruzzo, C. Ocean warming and spread of pathogenic vibrios in the aquatic environment. Microb. Ecol. 2013, 65, 817-825. [CrossRef] [PubMed]

12. Linares, C.; Coma, R.; Mariani, S.; Díaz, D.; Hereu, B.; Zabala, M. Early life history of the Mediterranean gorgonian Paramuricea clavata: Implications for population dynamics. Invert. Biol. 2008, 127, 1-11. [CrossRef]

13. Cerrano, C.; Bavestrello, G.; Bianchi, C.N.; Cattaneo-Vietti, R.; Bava, S.; Morganti, C.; Morri, C.; Picco, P.; Sara, G.; Schiaparelli, S.; et al. A catastrophic mass-mortality episode of gorgonians and other organisms in the Ligurian Sea (North-western Mediterranean), summer 1999. Ecol. Lett. 2000, 3, 284-293. [CrossRef]

14. Linares, C.; Coma, R.; Zabala, M. Restoration of threatened red gorgonian populations: An experimental and modelling approach. Biol. Conserv. 2008, 141, 427-437. [CrossRef]

15. Cerrano, C.; Bavestrello, G. Medium-term effects of die-off of rocky benthos in the Ligurian Sea. What can we learn from gorgonians? Chem. Ecol. 2008, 24, 73-82. [CrossRef]

16. Cerrano, C.; Bavestrello, G. Mass mortalities and extinctions. In Marine Hard Bottom Communities; Springer: Berlin/Heidelberg, Germany, 2009; pp. 295-307.

17. Garrabou, J.; Coma, R.; Bensoussan, N.; Bally, M.; Chevaldonné, P.; Cigliano, M.; Diaz, D.; Harmelin, J.G.; Gambi, M.; Kersting, D.; et al. Mass mortality in Northwestern Mediterranean rocky benthic communities: effects of the 2003 heat wave. Glob. Chang. Biol. 2009, 15, 1090-1103. [CrossRef]

18. Vezzulli, L.; Previati, M.; Pruzzo, C.; Marchese, A.; Bourne, D.G.; Cerrano, C. Vibrio infections triggering mass mortality events in a warming Mediterranean Sea. Environ. Microbiol. 2010, 12, 2007-2019. [CrossRef] [PubMed]

19. Huete-Stauffer, C.; Vielmini, I.; Palma, M.; Navone, A.; Panzalis, P.; Vezzulli, L.; Misic, C.; Cerrano, C. Paramuricea clavata (Anthozoa, Octocorallia) loss in the Marine Protected Area of Tavolara (Sardinia, Italy) due to a mass mortality event. Mar. Ecol. 2011, 32, 107-116. [CrossRef]

20. Santangelo, G.; Cupido, R.; Cocito, S.; Bramanti, L.; Priori, C.; Erra, F.; Iannelli, M. Effects of increased mortality on gorgonian corals (Cnidaria, Octocorallia): different demographic features may lead affected populations to unexpected recovery and new equilibrium points. Hydrobiologia 2015, 759, 171-187. [CrossRef]

21. Mokhtar-jamaï, K.; Pascual, M.; Ledoux, J.B.; Coma, R.; Féral, J.P.; Garrabou, J.; Aurelle, D. From global to local genetic structuring in the red gorgonian Paramuricea clavata: The interplay between oceanographic conditions and limited larval dispersal. Mol. Ecol. 2011, 20, 3291-3305. [CrossRef] [PubMed]

22. Coma, R.; Zabala, M.; Gili, J.M. Sexual reproductive effort in the Mediterranean gorgonian Paramuricea clavata. Mar. Ecol. Prog. Ser. 1995, 117, 185-192. [CrossRef] 
23. Coma, R.; Ribes, M.; Zabala, M.; Gili, J.M. Growth in a modular colonial marine invertebrate. Estuar. Coast. Shelf Sci. 1998, 47, 459-470. [CrossRef]

24. Cerrano, C.; Arillo, A.; Azzini, F.; Calcinai, B.; Castellano, L.; Muti, C.; Valisano, L.; Zega, G.; Bavestrello, G. Gorgonian population recovery after a mass mortality event. Aquat. Conserv. Mar. Freshw. Ecosyst. 2005, 15, 147-157. [CrossRef]

25. Mistri, M. Gross morphometric relationships and growth in the Mediterranean gorgonian Paramuricea clavata. Ital. J. Zool. 1995, 62, 5-8.

26. Weinbauer, M.G.; Velimirov, B. Biomass and secondary production of the temperate gorgonian coral Eunicella cavolini (Coelenterata: Octocorallia). Mar. Ecol. Prog. Ser. 1995, 121, 211-216. [CrossRef]

27. Deter, J.; Descamp, P.; Ballesta, L.; Boissery, P.; Holon, F. A preliminary study toward an index based on coralligenous assemblages for the ecological status assessment of Mediterranean French coastal waters. Ecol. Indic. 2012, 20, 345-352. [CrossRef]

28. Figueira, W.; Ferrari, R.; Weatherby, E.; Porter, A.; Hawes, S.; Byrne, M. Accuracy and Precision of Habitat Structural Complexity Metrics Derived from Underwater Photogrammetry. Remote Sens. 2015, 7, 16883-16900. [CrossRef]

29. Ferrari, R.; Figueira, W.F.; Pratchett, M.S.; Boube, T.; Adam, A.; Kobelkowsky-Vidrio, T.; Doo, S.S.; Atwood, T.B.; Byrne, M. 3D photogrammetry quantifies growth and external erosion of individual coral colonies and skeletons. Sci. Rep. 2017, 7, 16737. [CrossRef] [PubMed]

30. Palma, M.; Rivas Casado, M.; Pantaleo, U.; Cerrano, C. High Resolution Orthomosaics of African Coral Reefs: A Tool for Wide-Scale Benthic Monitoring. Remote Sens. 2017, 9, 705. [CrossRef]

31. James, M.; Robson, S. Straightforward reconstruction of 3D surfaces and topography with a camera: Accuracy and geoscience application. J. Geophys. Res. Earth Surf. 2012, 117. [CrossRef]

32. Wallace, L.; Lucieer, A.; Malenovskỳ, Z.; Turner, D.; Vopěnka, P. Assessment of forest structure using two UAV techniques: A comparison of airborne laser scanning and structure from motion (SfM) point clouds. Forests 2016, 7, 62. [CrossRef]

33. Raoult, V.; Reid-Anderson, S.; Ferri, A.; Williamson, J.E. How reliable is Structure from Motion (SfM) over time and between observers? A case study using coral reef bommies. Remote Sens. 2017, 9, 740. [CrossRef]

34. Bryson, M.; Ferrari, R.; Figueira, W.; Pizarro, O.; Madin, J.; Williams, S.; Byrne, M. Characterization of measurement errors using structure-from-motion and photogrammetry to measure marine habitat structural complexity. Ecol. Evolut. 2017, 7, 5669-5681. [CrossRef] [PubMed]

35. Royer, J.P.; Nawaf, M.M.; Merad, D.; Saccone, M.; Bianchimani, O.; Garrabou, J.; Ledoux, J.B.; Lopez-Sanz, A.; Drap, P. Photogrammetric Surveys and Geometric Processes to Analyse and Monitor Red Coral Colonies. J. Mar. Sci. Eng. 2018, 6, 42. [CrossRef]

36. Huete-Stauffer, C.; Previati, M.; Scinto, A.; Palma, M.; Pantaleo, U.; Cappanera, V.; Cerrano, C.; Imperia, C.E.A.; Portofino, M. Long-Term Monitoring in a Multi-Stresses Paramuricea clavata Population. Rapp. Comm. int. Mer Médit. 2013, 40, 654.

37. Atlante Degli Habitat Marini Sc. 1:10000-2009. Available online: http://geoservizi.regione.liguria.it/ geoserver / M1277 / wms? version=1.3.0\&request=getcapabilities (accessed on 30 May 2018).

38. Pergent, G. Proposal for the definition of standard methods for inventorying and monitoring coralligenous and maerl populations. In UNEP-MAP, RAC/SPA Report UNEP (DEPI)/MED WG; United Nations Environment Programme Mediterranean Action Plan Regional Activity Centre for Specially Protected Areas (RAC/SPA): Cedex, Tunis, 2011; Volume 362, p. 20.

39. Lepareur, F. Évaluation de l'état de conservation des habitats naturels marins à l'échelle d'un site Natura 2000. Guide Méthodol. Rapp. SPN 2011, 3, 9.

40. Mitchell, N.D.; Dardeau, M.R.; Schroeder, W.W.; Benke, A.C. Secondary production of gorgonian corals in the northern Gulf of Mexico. Mar. Ecol. Prog. Ser. 1992, 87, 275-281. [CrossRef]

41. Zuiderveld, K. Contrast limited adaptive histogram equalization. Graph. Gems 1994, 474-485. [CrossRef]

42. Girardeau-Montaut, D. CloudCompare, Version 2.6.0 (GPL Software). 2014. Available online: http:/ / www. cloudcompare.org/release/notes/20141026/ (accessed on 21 July 2018).

43. Lague, D.; Brodu, N.; Leroux, J. Accurate 3D comparison of complex topography with terrestrial laser scanner: Application to the Rangitikei canyon (NZ). ISPRS J. Photogramm. Remote Sens. 2013, 82, 10-26. [CrossRef] 
44. Kazhdan, M.; Hoppe, H. Screened poisson surface reconstruction. ACM Trans. Graph. (TOG) 2013, 32, 29. [CrossRef]

45. Brodu, N.; Lague, D. 3D Point Cloud Classification of Complex Natural Scenes Using a Multi-Scale Dimensionality Criterion: Applications in Geomorphology; EGU General Assembly: Vienna, Austria, 2012; Volume 14, p. 4368.

46. Cignoni, P.; Callieri, M.; Corsini, M.; Dellepiane, M.; Ganovelli, F.; Ranzuglia, G. MeshLab: An Open-Source Mesh Processing Tool. In Eurographics Italian Chapter Conference; Scarano, V., Chiara, R.D., Erra, U., Eds.; The Eurographics Association: Salerno, Italy, 2008.

47. Dewez, T.J.B.; Girardeau-Montaut, D.; Allanic, C.; Rohmer, J. Facets: A CloudCompare plugin to extract geological planes from unstructured 3d point clouds. ISPRS Int. Arch. Photogramm. Remote Sens. Spat. Inf. Sci. 2016, XLI-B5, 799-804. [CrossRef]

48. Schneider, C.A.; Rasband, W.S.; Eliceiri, K.W. NIH Image to ImageJ: 25 years of image analysis. Nat. Methods 2012, 9, 671-675. [CrossRef] [PubMed]

49. Linares, C.; Coma, R.; Garrabou, J.; Díaz, D.; Zabala, M. Size distribution, density and disturbance in two Mediterranean gorgonians: Paramuricea clavata and Eunicella singularis. J. Appl. Ecol. 2008, 45, 688-699. [CrossRef]

50. Bramanti, L.; Benedetti, M.C.; Cupido, R.; Cocito, S.; Priori, C.; Erra, F.; Iannelli, M.; Santangelo, G. Demography of Animal Forests: The Example of Mediterranean Gorgonians. In Marine Animal Forests: The Ecology of Benthic Biodiversity Hotspots; Rossi, S., Bramanti, L., Gori, A., Orejas Saco del Valle, C., Eds.; Springer: Cham, Switzerland, 2015; pp. 1-20.

51. Milazzo, M.; Chemello, R.; Badalamenti, F.; Camarda, R.; Riggio, S. The impact of human recreational activities in marine protected areas: What lessons should be learnt in the Mediterranean sea? Mar. Ecol. 2002, 23, 280-290. [CrossRef]

52. Rossi, S.; Gili, J.M.; Garrofé, X. Net negative growth detected in a population Leptogorgia sarmentosa: Quantifying the biomass loss in a benthic soft bottom-gravel gorgonian. Mar. Biol. 2011, 158, 1631-1643. [CrossRef]

53. Pavoni, G.; Palma, M.; Callieri, M.; Dellepiane, M.; Scopigno, R.; Cerrano, C. Quasi-Orthorectified projection for the measurement of Red Gorgonian colonies. ISPRS Ann. Photogramm. Remote Sens. Spat. Inf. Sci. 2018, XLII-2, 853-860. [CrossRef]

54. European Commission. Communication from the Commission to the Council, the European Parliament, the European Economic and Social Committee and the Committee of Regions COM(2006)421 and the Committee of the Regions; European Partnership: Brussels, Belgium, 2011.

55. Franzese, P.P.; Buonocore, E.; Paoli, C.; Massa, F.; Stefano, D.; Fanciulli, G.; Miccio, A.; Mollica, E.; Navone, A.; Russo, G.F.; et al. Environmental accounting in marine protected areas: The EAMPA project. J. Environ. Account. Manag. 2015, 3, 324-332. [CrossRef]

56. Coma, R.; Ribes, M.; Serrano, E.; Jiménez, E.; Salat, J.; Pascual, J. Global warming-enhanced stratification and mass mortality events in the Mediterranean. Proc. Natl. Acad. Sci. USA 2009, 106, 6176-6181. [CrossRef] [PubMed]

57. Cerrano, C.; Danovaro, R.; Gambi, C.; Pusceddu, A.; Riva, A.; Schiaparelli, S. Gold coral (Savalia savaglia) and gorgonian forests enhance benthic biodiversity and ecosystem functioning in the mesophotic zone. Biodivers. Conserv. 2010, 19, 153-167. [CrossRef]

58. White, M.; Wolff, G.A.; Lundälv, T.; Guihen, D.; Kiriakoulakis, K.; Lavaleye, M.; Duineveld, G. Cold-water coral ecosystem (Tisler Reef, Norwegian Shelf) may be a hotspot for carbon cycling. Mar. Ecol. Prog. Ser. 2012, 465, 11-23. [CrossRef]

59. Cathalot, C.; Van Oevelen, D.; Cox, T.J.; Kutti, T.; Lavaleye, M.; Duineveld, G.; Meysman, F.J. Cold-water coral reefs and adjacent sponge grounds: Hotspots of benthic respiration and organic carbon cycling in the deep sea. Front. Mar. Sci. 2015, 2, 37. [CrossRef]

60. Le, J.T.; Levin, L.A.; Carson, R.T. Incorporating ecosystem services into environmental management of deep-seabed mining. Deep Sea Res. Part II Top. Stud. Oceanogr. 2017, 137, 486-503. [CrossRef]

61. Franzese, P.P.; Buonocore, E.; Donnarumma, L.; Russo, G.F. Natural capital accounting in marine protected areas: The case of the Islands of Ventotene and S. Stefano (Central Italy). Ecol. Model. 2017, 360, 290-299. [CrossRef] 
62. Picone, F.; Buonocore, E.; D’Agostaro, R.; Donati, S.; Chemello, R.; Franzese, P. Integrating natural capital assessment and marine spatial planning: A case study in the Mediterranean sea. Ecol. Model. 2017, 361, 1-13. [CrossRef]

63. Sartoretto, S.; Schohn, T.; Bianchi, C.N.; Morri, C.; Garrabou, J.; Ballesteros, E.; Ruitton, S.; Verlaque, M.; Daniel, B.; Charbonnel, E.; et al. An integrated method to evaluate and monitor the conservation state of coralligenous habitats: The INDEX-COR approach. Mar. Pollut. Bull. 2017, 120, 222-231. [CrossRef] [PubMed]

(C) 2018 by the authors. Licensee MDPI, Basel, Switzerland. This article is an open access article distributed under the terms and conditions of the Creative Commons Attribution (CC BY) license (http://creativecommons.org/licenses/by/4.0/). 